\title{
Radon-220 Calibration of Near-Surface Turbulent Gas Transport
}

\author{
Bernhard E.Lehmann and Martin Lehmann \\ Physics Institute, University of Bern, Switzerland

\begin{abstract}
Albrecht Neftel and Andreas Gut
Institute for Environmental Protection and Agriculture (IUL), Bern-Liebefeld, Switzerland
\end{abstract}

\author{
Sergei V.Tarakanov \\ Institute of Silicate Chemistry, St.Petersburg, Russia
}

\begin{abstract}
Activity concentration profiles of the short-lived radon isotope ${ }^{220} \mathrm{Rn}$ (half-life 56 seconds) in the lowest $50 \mathrm{~cm}$ above the soil are used to study near-surface gas transport processes. The experimental data are compared to profiles calculated by solving the one-dimensional diffusion equation for radioactive atoms with a linear increase of the eddy diffusion coefficient $\mathrm{K}$ with altitude according to $\mathrm{K}(\mathrm{z})=\mathrm{K}_{0}+$ $\mathrm{K}_{\mathrm{z}} \mathrm{z}$. The slope $\mathrm{K}_{\mathrm{z}}$ in this model and the radon flux from the surface are continuously calculated from the activity measurements in time steps of one hour. Transport times for $\mathrm{Rn}$ atoms from an altitude $\mathrm{z}_{1}=5 \mathrm{~cm}$ to an altitude $\mathrm{z}_{2}=20 \mathrm{~cm}$ are typically between one and two minutes in stable meteorological conditions when the friction velocity $\mathrm{u}^{*}$ is below $0.1 \mathrm{~m} / \mathrm{s}$.
\end{abstract}

\section{Introduction}

Radon-220 is a radioactive noble gas isotope with a half-life of $\mathrm{T}_{1 / 2}=55.6$ seconds. Atoms are continuously generated in rocks and soils in the natural $\alpha$-decay series of ${ }^{232} \mathrm{Th}$ (which explains its historical name "thoron"); the mother radionuclide of ${ }^{220} \mathrm{Rn}$ is ${ }^{224} \mathrm{Ra}$. A fraction of the generated $\mathrm{Rn}$ atoms emanates from the site of production into the air-filled pore space of e.g. soil, from where some can escape to the atmosphere. Due to the short half-life of less than one minute ${ }^{220} \mathrm{Rn}$ atoms can only reach very low altitudes above the surface. For an eddy diffusion coefficient of $\mathrm{K}=10^{-3} \mathrm{~m}^{2} / \mathrm{s}$, for example, a characteristic vertical range is given by $\mathrm{z}^{*}=(\mathrm{K} /)^{1 / 2}$ $=28 \mathrm{~cm}$, where $\lambda$ is the radioactive decay constant of ${ }^{220} \mathrm{Rn}(\lambda$ $\left.=\ln 2 / T_{1 / 2}=0.0125 \mathrm{~s}^{-1}\right)$. Since radon is an inert gas no biochemical processes affect its concentration in air.

A knowledge of the atmospheric transport characteristics near the soil surface is crucial for the investigation of all biosphere-atmosphere exchange processes. State of the art micrometeorological techniques include e.g. eddy correlation or relaxed eddy correlation techniques. In times with stable meteorological conditions, however, turbulent exchange is so small that fluxes can no longer be determined by these methods. Using the radioactive decay of ${ }^{220} \mathrm{Rn}$, the rate of vertical gas exchange near the surface in such situations can be monitored with time series of vertical activity profiles.

Copyright 1999 by the American Geophysical Union.

Paper number 1999GL900026.

0094-8276/99/1999GL900026\$05.00
Radon isotopes have been used in a number of environmental studies. [for a review see e.g. Wilkening $M$., 1990]. Most of these investigations were based on the measurement of ${ }^{222} \mathrm{Rn}$, the most abundant radon isotope with a half-life of 3.82 days. Due to the analytical problems with such a short-lived isotope the use of ${ }^{220} \mathrm{Rn}$, however, has been rather limited [Schery, 1990]. Measurements were generally based on alpha-particle scintillation cells [Schery et al. 1989; Falk et al. 1992]. In a more recent study positively charged thoron daughter products were collected by an electric field and deposited onto surface-barrier $\alpha$-detectors for a continuous monitoring of ${ }^{220} \mathrm{Rn}$ in outdoor air [Butterweck G., et al., 1994]. In our report ${ }^{220} \mathrm{Rn}$ gas activities are directly measured with a rather simple automatic $\mathrm{Rn}$ gas monitor. Continuous measurements over extended time periods essentially without any maintenance enable a much more routine use of this isotope in environmental studies.

\section{Analytical Technique}

New commercial radon gas monitors (ALPHAGUARD Model PQ2000 PRO, Genitron Instruments, Frankfurt, Germany) have been combined with a microprocessor controlled gas sampling system for continuous monitoring of ${ }^{222} \mathrm{Rn}$ - and ${ }^{220} \mathrm{Rn}$-activity concentrations $\left(\mathrm{Bq} / \mathrm{m}^{3}\right)$ above and below the surface [Lehmann B.E. et al., 1997; Gut et al., 1998]. The detectors are based on digital signal processing of pulses from an ionization chamber and have a detection limit of about $3 \mathrm{~Bq} / \mathrm{m}^{3}$ for an accumulation time of 10 minutes. Each analytical unit contains a small membrane pump to transport air through an aerosol filter for removing radon daughter products before entering the detector. Programable valves switch between different inlet lines and pass the air sample either directly into the detector or through a delay volume where the ${ }^{220} \mathrm{Rn}$ atoms decay. Two detector units are currently available. For the data presented below they were operated in series : Air entered the first detector at a rate of 0.35 liters/minute and was then pumped into the delay volume of 2 liters. In the average transit time of 340 seconds more than $98 \%$ of the ${ }^{220} \mathrm{Rn}$ atoms decay before entering the second detector. This second monitor therefore measures ${ }^{222} \mathrm{Rn}$-activity only which then can be subtracted from the data of the first monitor to get the ${ }^{220} \mathrm{Rn}$-activity in the same time interval. A similar subtraction technique was also used e.g. by Schery and 
coworkers for the determination of radon and thoron fluxes from Australian soils [Schery et al., 1989].

\section{Time Series of ${ }^{220} \mathbf{R n}$-Activity Concentrations}

A continuous 6 -day record of ${ }^{220} \mathrm{Rn}$-activities at three different altitudes above the surface is presented in Figure 1. The time series is part of a longer run where the equipment was in the field for several weeks operating automatically without any maintenance or control work. The data were taken at our experimental field site Kerzersmoos which is located 20 $\mathrm{km}$ north-east of Bern in a flat rural area of the Swiss plateau with small, intensively cultivated agricultural plots. The monitors were placed into a field with a mixture of grass and clover, however, the plants around the inlet lines were cut down to avoid a canopy effect for the ${ }^{220} \mathrm{Rn}$ measurements. In this experiment the inlet altitude was sequentially switched between $\mathrm{z}_{1}=5 \mathrm{~cm}, \mathrm{z}_{2}=20 \mathrm{~cm}$ and $\mathrm{z}_{3}=50 \mathrm{~cm}$ above the surface every 20 minutes.

For each of these measuring intervals of 20 minutes the detectors synchronously measured two activity concentrations $\left(\mathrm{Bq} / \mathrm{m}^{3}\right)$, one every 10 minutes. The data of the first of these two intervals were ignored because after switching from one $\mathrm{z}$ level to the other a certain time is necessary to flush the system. The difference between the two detectors represents the (uncorrected) ${ }^{220} \mathrm{Rn}$-activity. From the known flow-rate and the volume of detector and inlet lines a correction for radioactive decay was calculated (factor of 2.1) to get the ${ }^{220} \mathrm{Rn}$-activity for the corresponding 20-minute time interval at the respective height. The resulting decay-corrected ${ }^{220} \mathrm{Rn}$-activity still needs to be corrected by the sensitivity of the detectors for ${ }^{220} \mathrm{Rn}$, a factor which is not easy to determine. The monitors are calibrated over several decades for ${ }^{222} \mathrm{Rn}$ by operating them inside a Rn chamber using certified gas standards. According to the manufacturer ${ }^{222} \mathrm{Rn}$ - and ${ }^{220} \mathrm{Rn}$-sensitivites should be almost identical due to the low energy resolution of the ionization chamber. However, this statement was not explicitly checked experimentally for the present study. Calibrations inside a thoron chamber are planned in order to quantify this uncertainty in future studies. Since the transport parameters (e.g. K-values, see below) derived from a vertical ${ }^{220} \mathrm{Rn}$-profile, however, rely on the ratios of activities at different altitudes

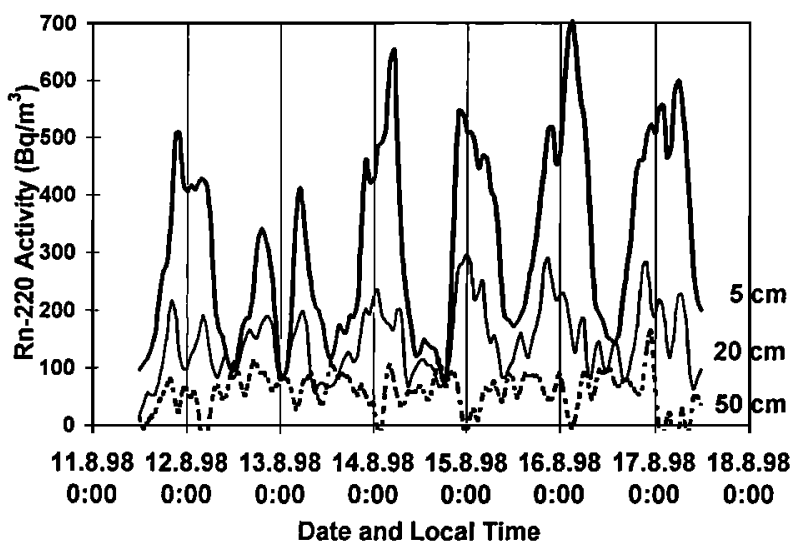

Figure 1. ${ }^{220} \mathrm{Rn}$-activity concentrations measured at three altitudes above the surface during one week.

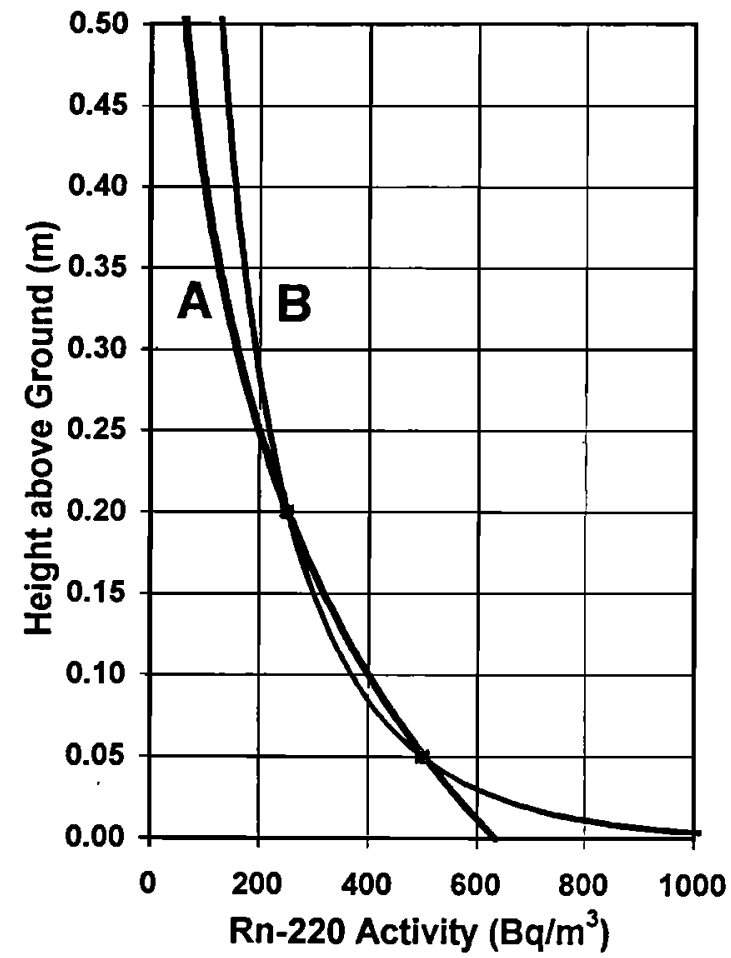

Figure 2. Calculated vertical activity concentration profiles for ${ }^{220} \mathrm{Rn}$ for a constant flux $\mathrm{j}$ from the soil to the atmosphere. A) $\mathrm{K}=$ constant; $\mathrm{B}) \mathrm{K}=\mathrm{K}_{0}+\mathrm{K}_{\mathrm{z}} \mathrm{z}$ (see text).

such a calibration is not important for this study. The procedure yields 24 data points each for all three levels per day. The three sets of data are shifted relative to each other by 20 (or 40) minutes. Linear interpolation was used to compare the three activities at a fixed time.

\section{Vertical ${ }^{220}$ Rn-Activity Concentration Profiles}

In a first approximation, the one-dimensional diffusion equation for radioactive atoms can be solved under the assumption that the eddy diffusion coefficient $\mathrm{K}\left(\mathrm{m}^{2} / \mathrm{s}\right)$ above the surface and the flux $\mathrm{j}\left(\mathrm{Bq} /\left(\mathrm{m}^{2} . \mathrm{s}\right)\right)$ from the soil to the atmosphere both are constant. This approach is mathematically simple but may not be very realistic. The integration for this case yields an exponential activity concentration profile as a function of altitude $\mathrm{z}$ above the surface according to $\mathrm{A}(\mathrm{z})=$ $A_{0} e^{-\left(z z^{*}\right)}$. The scale height $z^{*}$ is related to the diffusion coefficient $K$ and to the decay constant $\lambda$ by $z^{*}=(K / \lambda)^{1 / 2}$. The maximum specific activity $\mathrm{A}_{0}\left(\mathrm{~Bq} / \mathrm{m}^{3}\right)$ at the surface is given by $A_{0}=\left(j z^{*}\right) / K$. For such a steady-state situation the two unknown parameters $K$ and $j$ can be determined from two simultaneous activity measurements $\mathrm{A}\left(\mathrm{z}_{1}\right)$ and $\mathrm{A}\left(\mathrm{z}_{2}\right)$ at two different altitudes $\mathrm{z}_{1}$ and $\mathrm{z}_{2}$.

From Figure 1 typical activities during the night of $A_{5}=500$ $\mathrm{Bq} / \mathrm{m}^{3}$ and $\mathrm{A}_{20}=250 \mathrm{~Bq} / \mathrm{m}^{3}$ are selected to illustrate an average situation. From these data at $z_{1}=5 \mathrm{~cm}$ and $z_{2}=20 \mathrm{~cm}$ one calculates $\mathrm{K}=$ constant $=5.9 \cdot 10^{-4} \mathrm{~m}^{2} / \mathrm{s}$ and $\mathrm{j}=1.7$ $\mathrm{Bq} /\left(\mathrm{m}^{2} . \mathrm{s}\right)$. The respective exponential activity profile with a scale height of $z^{*}=22 \mathrm{~cm}$ is plotted as curve $A$ in Figure 2.

In a more realistic approach the 1-dimensional diffusion equation: 

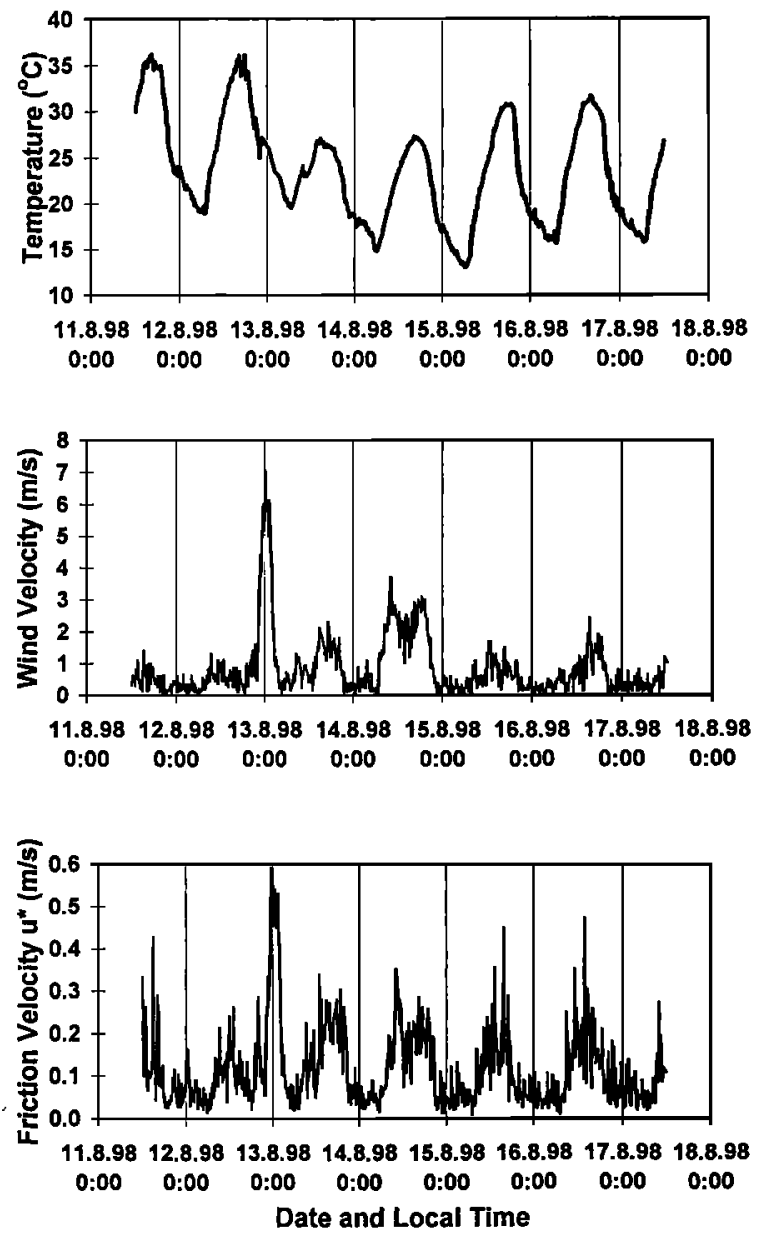

Figure 3. Temperature (top), horizontal velocity (centre) and friction velocity $\mathrm{u}^{*}$ (bottom).

$$
\partial_{t} n=\partial_{z}\left[K(z) \partial_{z} n\right]-\lambda n
$$

was solved with the boundary conditions

$$
-\left.K \partial_{z} n\right|_{z=0}=j,\left.\quad n\right|_{z=\infty}=0
$$

for the case where the diffusion coefficient of ${ }^{220} \mathrm{Rn}$ in air is a linear function of the height $\mathrm{z}$ above the surface according to

$$
K=K_{0}+K_{z} \cdot z \text {. }
$$

We set $K_{0}=1.2 \cdot 10^{-5} \mathrm{~m}^{2} / \mathrm{s}$, the value for molecular diffusion of $\mathrm{Rn}$ in air. ( $t$ is the time; $z$ is the height above the surface; $n$ is the concentration of ${ }^{220} \mathrm{Rn}$ - atoms per volume; $K$ is the diffusion coefficient, $j$ is the flux of ${ }^{220} \mathrm{Rn}$ through the surface, $\lambda$ is the radioactive decay constant of ${ }^{220} \mathrm{Rn}$ ).

The resulting profile that matches the two selected activities at $5 \mathrm{~cm}$ and $20 \mathrm{~cm}$ is plotted as curve $B$ in Figure 2. Numerical values of $\mathrm{K}_{\mathrm{z}}=1.510^{-2} \mathrm{~m} / \mathrm{s}$ and $\mathrm{j}=3.4 \mathrm{~Bq} /\left(\mathrm{m}^{2} \mathrm{~s}\right)$ result. The calculated $\mathrm{K}$ values at the two selected altitudes are then $\mathrm{K}_{\mathbf{5}}=$ $7.6 \cdot 10^{-4} \mathrm{~m}^{2} / \mathrm{s}$ and $\mathrm{K}_{20}=3 \cdot 10^{-3} \mathrm{~m}^{2} / \mathrm{s}$.

\section{Meteorological Data}

The selected week represents a rather constant meteorological situation with a sequence of hot summer days with temperature maxima between 27 and 36 degrees centigrade and noctural minimas between 13 and 19 degrees centigrade. Wind-speeds were generally below $2 \mathrm{~m} / \mathrm{s}$ during the day and below $0.5 \mathrm{~m} / \mathrm{s}$ at night. Meteorological data of this period including the friction velocity $\mathrm{u}^{*}$ determined by eddy correlation techniques at $2.5 \mathrm{~m}$ above ground are presented in Figure 3. Note the correspondence between the sharp decrease of the ${ }^{220} \mathrm{Rn}$-activity around midnight of the second day and strong winds during a short thunderstorm.

\section{Transport Parameters}

From the ${ }^{220} \mathrm{Rn}$ activity concentrations of Figure 3 an effective transport time $\tau$ from one height to the next can be calculated in a straightforward way by solving the decay equation $A_{2}=A_{1} e^{-\lambda . \tau}$, where $A_{1}$ and $A_{2}$ are the activity concentrations at altitudes $z_{1}$ and $z_{2}$. Such an approach is independent of any particular transport model and represents the essential physical information given by the ${ }^{220} \mathrm{Rn}$ clock. As can be seen in the top curve of Figure 4, it takes about 100 seconds to transport $R n$ atoms from the $5 \mathrm{~cm}$ to the $20 \mathrm{~cm}$ level at the end of a night when conditions are most stable.

In a next step the activity concentrations measured at the three altitudes (Figure 1) were fit to vertical profiles that would result from diffusion with a linear increase of the eddy diffusion coefficient $K$ according to

$$
K=K_{0}+K_{z} \cdot \mathbf{z} \text {. }
$$

as outlined above.

Values of the parameters $j$ and $K_{z}$ are determined based on the comparison of experimental data points and calculated concentration profiles by minimizing the difference

$$
R\left(j, K_{z}\right)=\left(\frac{1}{I} \sum_{i}^{I}\left(n\left(z_{i}\right)-n_{e x}\left(z_{i}\right)\right)^{2}\right)^{1 / 2},
$$

where $I$ is the total number of experimental points and $n_{e x}\left(z_{i}\right)$ is the measured value at altitude $z_{i}$ above the surface. The optimization procedure yields numerical values for $K_{z}$ the slope of the linear function $K(z)$, and for the flux $j$ from the surface. These calculated parameters are presented in the central and lower part of Figure 4.

\section{Discussion}

Micrometeorological flux determinations are usually based on eddy correlation techniques. In situations where the friction velocity $\mathrm{u}^{*}$ is below about $0.1 \mathrm{~m} / \mathrm{s}$ such an approach fails. As can be seen in the bottom curve of Figure 3 this occurs in all nights of the selected week. It is exactly in these situations when the ${ }^{220} \mathrm{Rn}$ method works best. The near-surface activities increase to rather high values and vertical profiles can easily be produced from the data of Figure 1. As was mentioned earlier, the most direct information one can then obtain is an average transport time from one altitude to another. The top curve in Figure 4 illustrates how these times vary throughout the week. In stable nights with almost no wind radon atoms need up to two minutes to pass from $z_{1}=5 \mathrm{~cm}$ to $z_{2}=20 \mathrm{~cm}$. The calculated slopes $\mathrm{K}_{\mathrm{z}}$ in our model with a linear $\mathrm{z}$-dependence of the eddy diffusion coefficent reach the lowest values of about $0.002 \mathrm{~m} / \mathrm{s}$ at these times. 

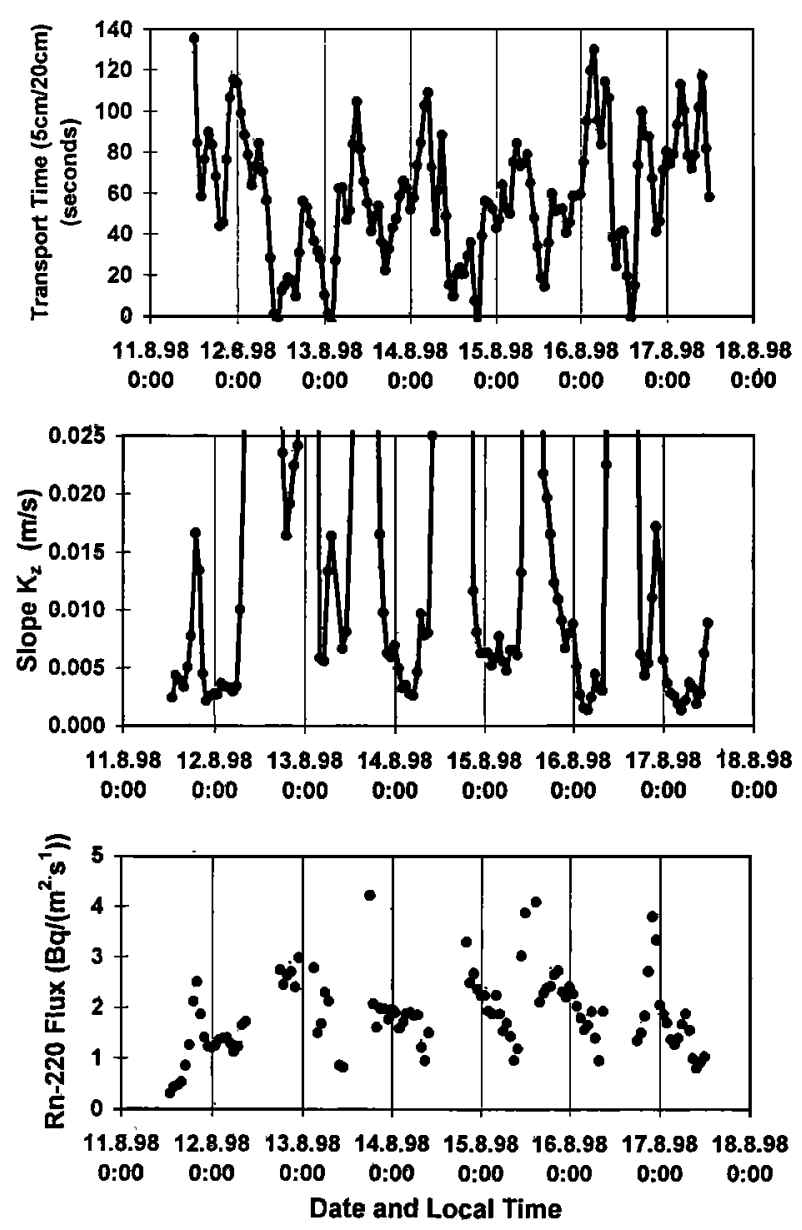

Figure 4. Calculated transport time from $5 \mathrm{~cm}$ to $20 \mathrm{~cm}$ altitude (top), calculated slope $\mathrm{K}_{\mathrm{z}}$ of the linear function $\mathrm{K}(\mathrm{z})$ (centre) and calculated ${ }^{220} \mathrm{Rn}$-flux $\mathrm{j}$ from the surface (bottom).

Characteristic K-values of $\mathrm{K}=1.1 \cdot 10^{-4} \mathrm{~m}^{2} / \mathrm{s}$ (at $\mathrm{z}=5 \mathrm{~cm}$ ) and of $K=4.1 \cdot 10^{-4} \mathrm{~m}^{2} / \mathrm{s}($ at $z=20 \mathrm{~cm})$ are then calculated from our model. These values can be compared to those calculated for neutral stratification by $\mathrm{K}=\mathbf{k} \cdot \mathrm{u}^{*} . \mathrm{z}$, where $\mathbf{k}$ is the von Karman constant (approx. 0.4). The friction velocity during the period addressed was on the order of $0.05 \mathrm{~m} / \mathrm{s}$ (from Figure 3) which yields $\mathrm{K}=1 \cdot 10^{-3} \mathrm{~m}^{2} / \mathrm{s}$ (at $\mathrm{z}=5 \mathrm{~cm}$ ) and $\mathrm{K}=4 \cdot 10^{-3} \mathrm{~m}^{2} / \mathrm{s}$ (at $\mathrm{z}=20 \mathrm{~cm}$ ). The conditions of the study were strongly stable, and hence the actual eddy diffusivities should have been lower than the neutral values, as indeed has been found.

Occasionally the development of noctural stability from the late evening to the early morning of the next day can be continuously monitored, e.g. in the night from Aug 15 to Aug 16. It is an important test for our fitting procedure to see if the calculated flux of ${ }^{220} \mathrm{Rn}$ atoms from the surface does not change with time during such a night when the meteorological and the soil conditions are almost constant. Indeed, the flux between 6 $\mathrm{pm}$ and 6 am of this night is quite constant at $2.2 \pm 0.34$ $\mathrm{Bq} /\left(\mathrm{m}^{2} . \mathrm{s}\right)$. The overall average flux for the full week is $1.99 \pm$ $1.05 \mathrm{~Bq} /\left(\mathrm{m}^{2} . \mathrm{s}\right)$, a value close to the average $1.7 \mathrm{~Bq} /\left(\mathrm{m}^{2} . \mathrm{s}\right)$ given e.g. by Schery and coworkers [Schery et al., 1989] in their systematic study of Australian soils.

In conclusion, we have demonistrated that the radioactive isotope ${ }^{220} \mathrm{Rn}$ with its half-life of $\mathbf{5 5 . 6}$ seconds is a perfect tool to study near-surface gas transport in stable situations when more conventional micrometeorological methods cannot be applied.

Acknowledgements. This project was supported by the Swiss National Science Foundation and the University of Bern. It is part of a Swiss collaboration within BIATEX-2 (Biosphere-AtmosphereExchange) of the European Environmental Research Programm EUROTRAC-II. The technical help of H.P.Moret and H.Riesen is greatly appreciated. Two anonymous reviewers made excellent suggestions to further improve the manuscript.

\section{References}

Butterweck G., A.Reineking, J.Kesten, J.Porstendorfer. The use of the natural radioactive noble gases radon and thoron as tracers for the study of turbulent exchange in the atmospheric boundary layer case study in and above a wheat field. Atmospheric Enviromment $28,12,1963-1969,1994$.

Falk R., H.Mơre, L.Nyblom : Measuring Techniques for Environmental Levels of Radon-220 in Air Using Flow-through Lucas Cell and Multipole Time Analysis of Recorded Pulse Events. Appl.Radiat.Isot., Vol.43, No.1/2, 111-118, 1992.

Gut, A., A.Blatter, M.Fahrni, B.E.Lehmann, A.Neftel, T.Staffelbach. A new membrane tube technique (METT) for continuous gas measurements in soils, Plant and Soil 198, 79-88, 1998.

Lehmann B.E., M.Lehmann, H.H.Loosli, A.Gut, A.Blatter, M.Fahrni, A.Neftel, T.Staffelbach. Use of temporal variations of radon activities in soil gas depth profiles for calibrating trace gas exchange in agro-ecosystems. In Isotope Techniques in the Study of Environmental Change, IAEA Symposium IAEA-SM-249/48, Proceedings 717-725, 1997.

Schery S.D., S. Whittlestone, K.P.Hart. The Flux of Radon and Thoron From Australian Soils. Journal of Geophysical Research, Vol.94, D6, 8567-8576, 1989.

Schery S.D. Thoron in the Environment. J.Air Waste Manage.Assoc. 40, 493-497, 1990.

Wilkening M. Radon in the Environment, in Studies in Environmental Sciences 40, Elsevier, 137 pages, 1990.

(Received September 21, 1998; revised December 4, 1998; accepted January 8, 1998.) 